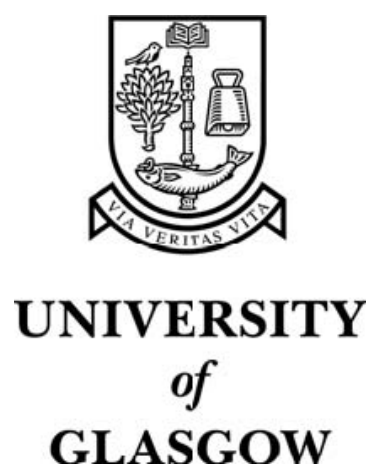

Danbolt, J. and Hirst, I. and Jones, E. (2002) Measuring growth opportunities. Applied Financial Economics 12(3):pp. 203-212.

http://eprints.gla.ac.uk/3690/ 


\title{
Measuring Growth Opportunities
}

\author{
Jo Danbolt*, Ian Hirst** and Edward Jones** \\ * Department of Accounting and Finance, University of Glasgow, 65-73 \\ Southpark Avenue, Glasgow G12 8LE. \\ ** Department of Accountancy and Finance, School of Management, Heriot-Watt \\ University, Riccarton, Edinburgh EH14 4AS.
}

\begin{abstract}
Although the impact of growth opportunities on company value has been recognised since Miller and Modigliani (1961), relatively little empirical work has been undertaken to value growth opportunities. In this paper we test the validity of the KBM model (Kester (1984) and Brealey and Myers (1981)) on a sample of 278 large UK companies for 1987-1995. Applying standard assumptions, we find the value of growth opportunities to account for a larger proportion of market values than assets-in-place. However, tests of the KBM model cast doubt on the credibility of these results and the validity of the model. The KBM model is highly sensitive to the inclusion of inflation in the risk free interest rate, and with a real interest rate (which on theoretical grounds is preferable), the model ceases to provide credible results. The model also fails to provide results consistent with expectations derived from option pricing theory regarding the relationship between the value of growth opportunities and the value of assets-in-place. These limitations of the KBM model indicate a need for a reappraisal of the method of measuring the value of growth opportunities.
\end{abstract}

Running Title: $\quad$ Measuring Growth Opportunities

JEL Classification: G30, G12

Address for correspondence:

Dr Jo Danbolt, Department of Accounting and Finance, University of Glasgow, 65-73 Southpark Avenue, Glasgow G12 8LE. E-mail: J.Danbolt@accfin.gla.ac.uk. Telephone: 0141330 6289. Fax: 01413304442. 


\section{Measuring Growth Opportunities}

\section{ABSTRACT}

Although the impact of growth opportunities on company value has been recognised since Miller and Modigliani (1961), relatively little empirical work has been undertaken to value growth opportunities. In this paper we test the validity of the KBM model (Kester (1984) and Brealey and Myers (1981)) on a sample of 278 large UK companies for 1987-1995. Applying standard assumptions, we find the value of growth opportunities to account for a larger proportion of market values than assets-in-place. However, tests of the KBM model cast doubt on the credibility of these results and the validity of the model. The KBM model is highly sensitive to the inclusion of inflation in the risk free interest rate, and with a real interest rate (which on theoretical grounds is preferable), the model ceases to provide credible results. The model also fails to provide results consistent with expectations derived from option pricing theory regarding the relationship between the value of growth opportunities and the value of assets-in-place. These limitations of the KBM model indicate a need for a reappraisal of the method of measuring the value of growth opportunities. 


\section{Measuring Growth Opportunities}

\section{INTRODUCTION}

Share prices can be decomposed into two elements - the value of "assets-in-place" and the value of growth opportunities. This distinction is central to the valuation of corporate equity (e.g. Miller and Modigliani, 1961), corporate financial structure (Myers, 1977), corporate cost of capital and capital budgeting decisions (Myers and Turnbull, 1977, and Majd and Pindyck, 1987).

Despite the importance of growth opportunities (also known as growth options), relatively little work has been done on how to identify the proportion of company value accounted for by the value of growth opportunities. Kester (1984) and Brealey and Myers (1981) developed a model (subsequently referred to as the KBM model) for separating the overall market value of a company into the value of assets-in-place and the value of growth opportunities. Kester $(1984,1986)$ and Brealey and Myers (1996) have demonstrated this decomposition for very small samples of major US corporations at a single point in time. Based on a sample of 15 companies, Kester (1984) argue that the present value of growth opportunities (PVGO) on average accounts for more than $50 \%$ of company market values. In his 1986 paper (based on a total sample of 9 companies split between 3 industries), Kester find PVGO to account for approximately 56 percent of total market value for electronics companies, 43 percent for chemicals companies, and 48 percent for paper companies. Similarly, Brealey and Myers (1996 p. 71) find that, for their set of 5 "income" stocks, PVGO accounts, on average, for 34\% of 
total market value. For the 5 "growth" stocks, PVGO accounts for approximately $66 \%$ of the total market values.

The purpose of this paper is to develop tests for the validity of the KBM model, and to apply these tests to estimates of the PVGO for a sample of 278 UK companies drawn from the FTSE 350 index over the period 1987-1995. We also discuss the appropriate choice of parameters for the model and measure the sensitivity of the KBM model to these decisions.

The KBM model is simple and unsophisticated. It can be argued that subjecting it to empirical tests is an inappropriate exercise. We have two replies to this. Firstly, we believe that the measurement of growth opportunities is an important, practical issue in finance. It is an empirical question whether simple measurement techniques are effective. Only if simple techniques are empirically discredited are we justified in looking for new measures. It is therefore appropriate that measurement methods should be tested, and one contribution of this paper is to develop, and employ, appropriate empirical tests. Secondly, the KBM model is very widely taught. This alone suggests that it should be subjected to critical empirical analysis.

Applying standard assumptions, we find (consistent with evidence for the US by Kester (1984, 1986) and Brealey and Myers (1996)), that the value of growth opportunities appears to account for a larger proportion of the market value of British companies than the value of assets-in-place. However, tests of the KBM model cast doubt on the credibility of these results and the validity of the model. While our tests show the KBM model to provide estimates of growth opportunities and assets-in-place which have the properties predicted for distinct financial assets, other tests of the model reveal several 
problems. The KBM model is highly sensitive to the inclusion of inflation in the risk free interest rate, and with a real interest rate (which on theoretical grounds is preferable), the model ceases to provide credible results. The model also fails to provide results consistent with expectations derived from option pricing theory regarding the relationship between the value of growth opportunities and the value of assets-in-place. These limitations of the KBM model for decomposing share values indicate a need for a reappraisal of the method of measuring the value of growth opportunities.

The remainder of the paper is organised as follows: In section 2 we provide an overview of the growth opportunities literature, while section 3 contains a detailed explanation of the KBM model for measuring growth opportunities. Our hypotheses are specified in section 4, while discussions of the data and definitions are provided in section 5 . The results are discussed in section 5, while section 6 provides a summary and conclusions.

\section{GROWTH OPPORTUNITIES LITERATURE}

Miller and Modigliani (1961) split firm value into:

- the present value of the uniform, perpetual earnings on assets currently held, and

- the present value of the opportunities that the firm offers for making additional investments in real assets that will yield more than the "normal" (market) rate of return.

Both present value calculations are made using the same "cost of capital" discount rate.

Myers (1977) records the distinction as between: 
- assets that can be regarded as call options to purchase real assets where ultimate value depends on further discretionary investment by the firm, and

- real assets with a market value which does not depend on further discretionary investment.

Myers notes specifically that maintenance of plant and equipment is a discretionary investment and that the continuance of the firm's current activities is therefore discretionary. Real options are not simply associated with potential growth. Despite this tangential comment, the distinction used throughout most of his paper is that between growth opportunities and the market value of cash flows from assets-in-place.

Myers and Turnbull (1977) extend the options analogy to recognise that the systematic risk of the firm's real options may differ from the systematic risk of its real assets and that investors may require different expected rates of return on them.

Pindyck (1988) takes the analogy further. The firm's real assets are identified as the firm's "capacity" and the real options are options to add more units of capacity in the future. He makes explicit the analogy between an investor's financial call option to acquire a share and a firm's real options to acquire additional units of capacity. We term this specific theoretical characterisation of growth opportunities the "call option analogy”.

\section{THE KBM MODEL FOR MEASURING GROWTH OPPORTUNITIES}


Kester (1984) and Brealey and Myers (1981) have drawn on this theoretical background to develop a model for the decomposition of share prices. In both cases, the share value due to assets-in-place (Px) is given by

$$
P x=\frac{E P S}{k}
$$

The assets-in-place are assumed to generate the firm's initial level of earnings-per-share (EPS) in perpetuity. This is valued at a discount rate $(\mathrm{k})$. The use of EPS, rather than operating cash flow, must reflect a decision to separate out the value of discretionary opportunities which will grow the business, rather than the value of all discretionary investments which would include the maintenance of current capital assets. ${ }^{1}$

The component of growth opportunities in the share price, Pg, is a residual which comes from subtracting $\mathrm{P}_{\mathrm{X}}$ from the market price of the firm's shares $(\mathrm{Pe})$ :

$$
P g=P e-P x
$$

For EPS, Kester (1984) uses the forecast earnings for a single year. If his market price is observed in month $\mathrm{t}$, his EPS is the Value Line forecast, at $\mathrm{t}$, for the year running from month $t-7$ to month $t+4$. He uses several values for $k$, ranging from $15 \%$ to $25 \%$, without offering any specific justification. He uses the same rates for all the companies in his sample. ${ }^{2}$

Brealey and Myers (1996) use an EPS which is an average of the forecast for the current year (months $t-2$ to $t+9$ ) and the subsequent year (months $t+10$ to $t+21$ ). They estimate 
$\mathrm{k}$ using the CAPM. Their risk free rate is the current, short-term, nominal rate. Their 8's are published estimates and their equity risk premium is $8.4 \%$ reflecting US experience over the period 1926 to 1994.

By using forecast earnings, both Kester (1984) and Brealey and Myers (1996) avoid the one-off company-specific surprises that may affect earnings outcomes. By averaging over two years, Brealey and Myers make some effort to avoid the economy-wide factors that may depress or raise corporate earnings in any particular year. If the economic cycle lasts longer than 2 years, however, the effectiveness of this procedure may be in doubt. As part of our sensitivity analysis, the empirical section of this paper investigates the effects of using different procedures to estimate EPS, and measure the extent to which the proportion of company values accounted for by the value of growth opportunities varies significantly over time.

There are three areas where alternative approaches can be used in the estimation of $\mathrm{k}$ :

a) Brealey and Myers (1996) explicitly, and Kester (1984), it would appear, implicitly, use a nominal risk free rate. This implies that the EPS figures are treated as perpetuities in nominal terms. It seems difficult to justify an assumption that the real EPS of UK corporations should decline at exactly the same rate as the purchasing power of the British pound. We would therefore argue that there is a case for using a method of decomposition that is not so heavily influenced by the level of expected inflation in the company's reporting currency at the time of the calculation. We therefore include in our analysis a calculation which treats the EPS as a perpetuity in real terms and discounts it at a 
real rate. We shall not consider further how changing levels of inflation might bias the calculation of the EPS figure itself.

b) Brealey and Myers (1996) use the CAPM with a historic US equity risk premium of $8.4 \%$. There is a substantial literature on the estimation of this number. Fama and French (1997) report a standard error in such historically based estimates of 2.71\%. An equivalent long-term historic estimate for the UK (based on 19191995 data) would, according to BZW (1996), be 9.06\% (arithmetic mean) and 8.66\% (geometric mean). An alternative choice of cut-off date within the period covered by our data makes very little change in these figures.

There are several non-historical methods of estimating the equity risk premium $\left(R_{P}\right)$ which generally produce lower values (O'Hanlon and Steele, 1997). These authors state "[our] results suggest that the premium is in the region of $4 \%$ to $5 \%$. This lends support to the suggestion that the ex-ante equity risk premium is substantially less than the historical average of the excess of equity returns over the risk-free rate" (abs.). This paper therefore investigates the sensitivity of the estimated value of growth opportunities to changes in the Rp estimate.

c) Brealey and Myers (1996) use the 8 of the share to derive the discount rate for the earnings from assets-in-place. As Myers and Turnbull (1977) have pointed out, the risk levels of the two components of share value are likely to differ. In particular, if Pg stands in relation to Px as the price of a call option to an underlying share (which should be the case if growth opportunities are options to expand current capacity), we would expect the appropriate discount rate for assets-in-place to be less than that for the whole share (which, in turn, would be 
less than the rate for the growth opportunities component). We therefore consider the sensitivity of measures of Pg and Px to the assumptions made about the division of risk between the two components.

Pindyck (1988) makes a striking claim about the practical significance of growth opportunities in share values. He states "That an implication of the model is that, for many firms, the fraction of market value attributable to the value of capital in place should be one-half or less" (p 979). However, his paper is based on a very specific mathematical model of firm investment decisions. It includes a stochastic demand function for the firm's product as well as a cost function. Pindyck's conclusion concerning the proportion of market value attributable to growth opportunities does not seem to be the result of substantial empirical analysis. The empirical evidence provided tenuously supports only one of the variables in the model, namely product price variability. $^{3}$ 


\section{HYPOTHESES}

To assess the validity of the KBM model of share price decomposition, we test the estimated values of Px and Pg against the following four hypotheses derived from the growth opportunities and option pricing literature.

\section{Hypothesis 1}

If the company has discretion with regard to whether or not to undertake the investment required to implement the growth opportunity (i.e., the exercise of growth options are voluntary), the value of growth opportunities should not be negative. As argued by Brealey and Myers (1996, p. 69), companies are seldom forced to undertake negative NPV investments. Similarly, if growth opportunities are analogous to options, it follows from the option pricing theory (Black and Scholes, 1973) that options should not have negative values. If the firm is not compelled to take up future growth opportunities, and we assume management aim to maximise shareholder wealth, the investment opportunities will only be accepted if they offer a return above the required "market" rate. Under these circumstances we predict that the values of growth opportunities should be non-negative.

H1a: The value of $P_{g} \geq 0$

Could assets-in-place have a negative value? On the basis of the "call option analogy" used by Pindyck (1988) the answer would be "no". An option to acquire capacity only has value if capacity has value. If Px were zero or negative, Pg would be zero and the whole share would be valueless. We shall therefore test the hypothesis that Px is nonnegative. 
H1b: $\quad$ The value of $P_{x} \geq 0$

Rejection of hypotheses H1a or H1b would suggest that the KBM is not reliable as a method of decomposing share values into the values of assets-in-place and the value of growth opportunities. $^{4}$

\section{Hypothesis 2}

Myers (1977) clearly envisages a situation in which growth opportunities might be distinct marketable assets, although he also envisages that this market might be imperfect. If Pg and Px are potentially distinct assets and the market in these assets is sufficient to allow an assumption of at least weak form market efficiency (Fama, 1991), then we would expect the abnormal returns on the values of assets-in-place and on the values of growth opportunities to exhibit the usual time-series properties of asset returns. We would expect both assets to exhibit abnormal returns which are not serially correlated. In addition, we would also expect the serial cross-correlation between the abnormal returns on assets-in-place $\left(\mathrm{ABR}_{x}\right)$ and on growth opportunities $\left(\mathrm{ABR}_{g}\right)$ to be zero.

Calculation of abnormal returns using the standard CAPM requires an asset 8 . We have a share 8 but no 8 for the two components. The assumption that all three 8 's are equal (though implicit in the standard decomposition method) seems restrictive. If the growth-opportunities asset has an option-like character, this would suggest that its risk level would be higher than the underlying asset. Indeed, Myers and Turnbull (1977) argue that the risk characteristics of assets-in-place will be different from the associated share, leading investors to require a higher rate of return on Pg than on Px. This would 
imply that $8 \mathrm{~g}>8 \mathrm{x}$, although their paper do not discuss the extent to which $8 \mathrm{~g}$ will exceed 8x. To test the sensitivity of our results to the assumption regarding the relative riskiness of the constituent assets, we report results for:
i) $\quad 8 \mathrm{x}=8 \mathrm{~g}$
ii) $\quad 28 \mathrm{x}=8 \mathrm{~g}$

\section{H2a: $\operatorname{CORR}\left(A B R x_{t}, A B R x_{t+1}\right)=0$ \\ H2b: $\operatorname{CORR}\left(A B R g_{t}, A B R g_{t+1}\right)=0$ \\ H2c: $\operatorname{CORR}\left(A B R x_{t}, A B R g_{t+1}\right)=0$ \\ H2d: $\operatorname{CORR}\left(A B R g_{t}, A B R x_{t+1}\right)=0$}

Rejection of any of the sub-hypotheses of $\mathrm{H} 2$ would suggest, either that the two components of share value are not distinct long-lived assets which conform to the predictions of the Efficient Market Hypothesis, or that the $\mathrm{KBM}$ model for decomposing share values into Px and Pg is unreliable.

Myers notes that the process which generates growth opportunities is unclear. They might pop into existence for reasons outside the scope of the model. He also notes that the value of growth opportunities must decline if not exercised. It would therefore be possible to envisage that growth options are short-lived phenomena, and that the set of future opportunities available at one year end would have very little connection to the set of opportunities a year later.

However, if the present value of growth opportunities account for a substantial proportion of share value and the annual level of firms' investments in new assets is 
comparatively low, this would imply that growth opportunities are long-lived options that stretch out over a substantial period of time. If this is accepted, H2 is a good test of the KBM model.

\section{Hypothesis 3}

Based on the "call option analogy", we would predict that movements in Px and Pg would be strongly correlated. Ceteris paribus, an option gains in value when the underlying asset rises in price. This is a property of standard option pricing models including Black and Scholes (1973), and Cox et al. (1979). This relationship would also apply to the abnormal returns on the two assets. Abnormal returns are used in the tests for reasons explained below.

H3: $\quad \operatorname{CORR}\left(A B R x_{t}, A B R g_{t}\right)$ is large and positive.

\section{Hypothesis 4}

Again, based on the "call option analogy", we predict that both the absolute values of ABRx and ABRg will have the same sign, and that the absolute value of ABRg will be greater than the absolute value of ABRx. This is a standard property of option pricing models. If this hypothesis is backed up by empirical evidence, it would support the Myers and Turnbull (1977) conjecture that risk levels (and hence investors' required returns) differ (and are lower) for assets-in-place than for whole shares.

H4: $\quad \frac{\mathrm{ABRg}}{\mathrm{ABRx}}>1$ 
Note that, if H3 and H4 are rejected, this might imply a failure of the KBM model, although it might also imply that the nature of growth opportunities does not fit the "call option analogy" that can be derived from Pindyck's (1988) work.

Since our data cover only 10 years and we are using annual returns, our data include only a small sample of market returns. We therefore calculate abnormal returns (ABRx, ABRg) using the standard CAPM equations. Using abnormal returns enhances the statistical efficiency of the tests. Option pricing models suggest that other variables, such as interest rates, might also be significant factors in growth option value, but, for the same reason, our data set is not suitable for incorporating such factors into the analysis.

\section{DATA AND DEFINITIONS}

Data for the empirical analysis were obtained from Datastream and the London Business School Risk Measurement Service for all firms in the FTSE 350 (where data was available) for a ten-year period from 1 January 1986 to 31 December 1995 . The final sample comprises 2082 annual observations for 278 companies. ${ }^{5}$ The analysis requires data for share price, earnings per share, beta, the real and nominal risk-free interest rates and the market risk premium. The data were obtained as follows:

Share price (Pg) - Price per share was obtained from Datastream International. The share price was taken as of the end of the financial year. 
Beta (8e) - Beta values for shares in the sample were obtained from the London Business School Risk Measurement Service from quarterly issues closest to the financial year-ends.

Nominal risk-free interest rate (kf) - The UK inter-bank 1 year middle rate was used as the nominal rate of interest.

Real risk-free rate $(\mathrm{kr})$. - This was taken from the return on short-dated index-linked securities issued by the UK government.

Both $\mathrm{kf}$ and $\mathrm{kr}$ were obtained from Datastream for the date of each observation.

Earnings per share (EPS) - Two measures were collected. The first, $\left(\mathrm{EPS}_{0}\right)$ is the forecast figure for the financial year which ended on the date the share price was recorded. This number would be announced some weeks after the year-end. The second (EPS $)_{1}$ is the consensus forecast at the year-end for the following year. Both these figures are I/B/E/S earnings forecasts obtained from Datastream. The average of these two measures is termed $\mathrm{EPS}_{1 / 2}$.

Equity risk premium (Rp) - Brealey and Myers use a US figure based on historic evidence. We use 9\% which closely fits UK data (BZW, 1996). However, the literature cited earlier suggests a wide range of estimates for this value derived by different methods, tending to support a market risk premium less than $9 \%$. We show additional calculations for $\mathrm{Rp}=3 \%$ and $6 \%$. In this way we span the range covered by the various estimation methods. 
Our measures of returns for the two components of company value are defined as follows:

i) The return on the financial asset associated with the assets-in-place is

$$
R X_{t}=\frac{P X_{t+1}-P X_{t}+D_{t}}{P X_{t}}
$$

ii) The return on the growth opportunities asset is

$$
R g_{t}=\frac{P g_{t+1}-P g_{t}}{P g_{t}}
$$

These are both crude measures of return which have an element of bias. Myers (1977) has pointed out that the value of a firm's growth options will tend to decline over time as some of the options expire. Since we make no allowance for this, Rg will have a consistent downward bias. Similarly Rx will be overestimated, as it includes gains which are the result of exercising options. If the value of these biases is assumed constant, however, they will not affect the validity of our tests.

\section{RESULTS}

\subsection{Characteristics of UK growth opportunities measured using the KBM method}

We estimate the value of growth opportunities for 2082 company year-ends for the 1987-1995 period using the KBM model. Consistent with Brealey and Myers (1996), 
we use a historic market risk premium (Rp) of 9\% and use $\mathrm{EPS}_{1 / 2}$. Exhibit 1 shows the mean, median, lower quartile and upper quartile by year and overall ${ }^{6}$. As a check on survivorship bias, the mean figures for the 172 firms for which data was available in every year are also shown. There is no significant difference between the means (annual and overall) for the total sample and those for surviving firms, indicating that the overall results are not driven by survivorship bias.

\section{Insert Exhibit 1 here}

These figures would appear to confirm, using UK data, the findings of Kester (1984, 1986), Brealey and Myers (1996) and Pindyck (1988) for the US. According to the KBM model, growth opportunities, on average, account for more than half of the companies market values in every year. The mean proportion of share value accounted for by growth opportunities ranges from a low of 50\% in 1988 (following the stock market crash in October 1987) to a peak of just over 61\% in 1992 when stock market prices reflected improved prospects for the UK economy. 


\subsection{Sensitivity of growth opportunity estimates}

We measure the sensitivity of the results to the parameterisation of EPS, the equity risk premium and the risk free interest rate.

\section{i) The measure of EPS}

The forecast of earnings in the forthcoming year tends to be higher than the earnings outcome for the current year. Hence the use of EPS 1 instead of $\mathrm{EPS}_{1 / 2}$ tends to raise the value of assets-in-place and lower the estimate of the proportion of value due to growth opportunities. The use of $\mathrm{EPS}_{0}$ has the opposite effect. The effect of the changes is comparatively minor.

\section{Insert Exhibit 2 here}

ii) The equity risk premium

Exhibit 3 shows that the valuation of growth opportunities is highly sensitive to the risk premium applied. If the equity risk premium is less than $9 \%$ (as suggested e.g., by O’Hanlon and Steele (1997)), the estimated values of Pg fall substantially.

\section{Insert Exhibit 3 here}

iii) The risk free rate

We have argued that the logic of growth opportunity valuation would lead to the use of a real rather than a nominal risk-free rate. Exhibit 4 shows estimates of the value created by growth opportunities when $\mathrm{kf}$ is replaced by $\mathrm{kr}$, for 3 values of the equity risk premium. 


\section{Insert Exhibit 4 here}

These numbers make it clear that valuation of growth opportunities is extremely sensitive to the inflation component of interest rates. With inflation removed, the present value of cash flows from assets-in-place rise substantially, with a commensurate fall in PVGO.

The results of decomposing UK share prices into assets-in-place and growth opportunities are consistent with the assertion that growth opportunities should account for more than 50\% of company value (Pindyck, 1988) when we use Brealey and Myers’ assumptions of a nominal interest rate and applying a historical equity risk premium of 9\%. However, Pg appears to be highly sensitive to the discount rate. When measured using a real rate of interest and a lower (and perhaps more realistic) risk premium, the value of growth opportunities accounts for a much smaller proportion of market value. This suggests that growth opportunities, whilst still of importance, may account for substantially less than $50 \%$ of company market values.

\subsection{Tests of Hypotheses}

Hypothesis 1

Hypothesis 1 predicts that the value of growth opportunities should not be negative (H1a) since exercise of the option is voluntary. The value of assets-in-place should also be positive since an option only has value if the underlying asset has value (H1b). When the standard Brealey and Myers assumptions are used with a 9\% equity risk premium, the credibility of the method is supported by the fact that the proportion of estimates outwith $0 \%-100 \%$ is low (3.5\%). However, H1a and H1b can be rejected for a larger proportion of the data when these assumptions are relaxed. 
With inflation removed, the proportion of negative values of Pg rises from $2.4 \%$ to $12.1 \%$ at a risk premium of $9 \%$. As the risk premium falls below $9 \%$, the calculations quickly lose credibility, as the proportion of negative values rises. The credibility of the model is stretched by the contrast between a basic theoretical model in which inflation is not discussed and empirical results which are highly sensitive to the distinction between a real and a nominal rate. When a real rate of interest and an equity risk premium of $3 \%$ are used, $62.1 \%$ of cases are outwith the range $0-100 \%$. In particular as the discount rate is reduced, the number of cases of $\mathrm{Pg}<0 \%$ increases.

As argued previously, the assumption made by Kester $(1984,1986)$ and Brealey and Myers (1996) that EPS from assets-in-place is fixed in nominal terms is problematic. However, the results in Exhibit 4 clearly show that once this assumption is relaxed (and the EPS is assumed to grow in line with inflation), the KBM model for valuing growth opportunities loses credibility.

\section{Hypothesis 2}

Hypothesis 2 suggests that if assets-in-place and growth opportunities are potentially distinct financial assets, the abnormal returns on these assets should exhibit zero serial correlation and cross-correlation.

\section{Insert Exhibit 5 here}

Exhibit 5 shows that serial correlations and cross-correlations are low and statistically insignificant in all cases except the serial cross-correlation between the abnormal return on the share in time period $\mathrm{t}\left(\mathrm{ABRg}_{\mathrm{t}}\right)$ and the abnormal return on assets in place during 
the following period $\left(\mathrm{ABRx}_{\mathrm{t}+1}\right)$. The results seem insensitive to the assumptions about the relative 8's of the two assets. With the one somewhat anomalous result, the standard decomposition method does credibly divide share prices into two parts which have some of the properties of distinct financial assets.

\section{Hypothesis 3}

The remaining hypotheses test whether the value of a firm's growth options relate to the value of its assets-in-place in the same way that the value of a financial call option relates to the value of the underlying share.

H3 predicts a strong co-temporaneous correlation between the abnormal return on assets in place $\left(A B R x_{t}\right)$ and the abnormal return on growth opportunities $\left(A B R x_{t}\right)$. The relationships between $A B R x_{t+1}, A B R x_{t}$ and $A B R g t$ are also shown in Exhibit 5 .

It is not surprising to find that $\mathrm{ABRg}_{\mathrm{t}}$ is correlated with the abnormal returns on the two assets which, together, make up total share value. The finding that $A B R x_{t}$ and $A_{B R g}$ are almost completely uncorrelated, and that the correlation is in fact very slightly negative, gives no support to the "call option analogy". Either the options analogy is misconceived or the KBM model for share decomposition is substantially in error.

\section{Hypothesis 4}

H4 predicts that the elasticity of changes in growth option value with respect to changes in the value of asset-in-place will be greater than unity. We therefore test the hypothesis that: 


$$
\frac{A B R g_{t}}{A B R x_{t}}>1
$$

In light of the result of testing H3, it is perhaps not surprising that the "call option analogy" fails again. Exhibit 6 shows the result of a binomial test of the hypothesis that the mean value:

$$
\frac{A B R g_{t}}{A B R x_{t}}=1
$$

Out of 1687 observations, only 470 have a value greater than 1 and the hypothesis that our sample is drawn from an underlying population with a mean equal to 1 is clearly rejected. The possibility of an underlying population elasticity greater than 1 would be rejected even more strongly.

Insert Exhibit 6 here 


\section{SUMMARY AND CONCLUSIONS}

We have tested the validity of the KBM (Kester (1984) and Brealey and Myers (1981)) model for measuring growth opportunities on a sample of 278 large UK companies for 1987-1995. This investigation into the measurement of growth opportunities for UK shares has produced mixed results. The findings have confirmed that, using standard methods developed in the US, the value of British companies, like their American counterparts, appears to be composed more of growth opportunities than current assetsin-place. Tests also confirmed that the values of growth opportunities and assets-inplace passed simple tests of credibility as potentially distinct financial assets.

However, the results also showed that the KBM method of measuring growth opportunities was undermined when inflation was removed from the risk-free interest rate. Since there is no strong theoretical reason to include inflation, this seems to indicate a weakness in the KBM model. If real interest rates are used alongside an equity risk premium below 9\%, the model ceases to give credible numbers.

The hypothesis that the value of a firm's growth options is linked to the value of assetsin-place in the same way that the value of a financial call option is linked to the value of an underlying share is clearly rejected for the KBM estimates of growth opportunities. This could be due either to limitations in the KBM model for decomposing share values into the value of assets-in-place and the value of growth opportunities, or due to growth options not possessing the same characteristics as traded options (e.g., if they are not options to expand the current capacity of the firms but have quite different characteristics). 
These results are entirely consistent with the view that growth opportunities form a significant part of stock market values and that they play a major role in rational financial decisions. However, our evidence demonstrates that that the KBM measurement technique does not appear to be robust in the face of reasonable changes in the model's parameters, and that the numbers generated are inconsistent with the "call option analogy" element in the growth opportunities literature. We conclude that there exists an opportunity to develop alternative measurements techniques which might provide a better fit between theory and observation.

\section{ACKNOWLEDGEMENTS}

The authors would like to express their thanks to Pauline Weetman, the participants at the British Accounting Association Annual Conference 1999 at the University of Glasgow, and the participants at the European Financial Management Association Annual Conference 1999 in Paris (in particular Ameziane Lasfer, the discussant) for constructive comments on earlier versions of this paper. Gratitude is also expressed to Kathy Birnie and Lynn McGee for research assistance, and to Kirsty MacCallum for library assistance. 


\section{REFERENCES}

Barclay M.J., and Smith C.W. (1995) The maturity structure of corporate debt, Journal of Finance, 50(2, June), 609-632.

Ben-Horim, M., and Callen, J.L. (1989) The Cost of Capital, Macaulay's Duration, and Tobin's q, Journal of Financial Research, 12(2, Summer), 143-156.

Black, F., and Scholes, M. (1973) The Pricing of Options and Corporate Liabilities, Journal of Political Economy, 81(May-June), 637-654.

Brealey, R.A., and Myers, S.C. (1981) Principles of Corporate Finance, (1 ${ }^{\text {st }}$ Edition), McGraw-Hill.

Brealey, R.A., and Myers, S.C. (1996) Principles of Corporate Finance, (5 ${ }^{\text {th }}$ Edition), McGraw-Hill.

BZW (1996) The BZW Equity-Gilt Study, BZW Securities, London.

Chung, K.H., and Charoenwong, C. (1991) Investment Options, Assets in Place, and the Risk of Stocks, Financial Management, 20(3, Autumn), 21-33.

Cox J., Ross, S., and Rubenstein M. (1979) Option Pricing: A Simplified Approach, Journal of Financial Economics, 7(September), 229-263.

Fama, E.F. (1991) Efficient Capital Markets II, Journal of Finance, 46(5, December), 1575-1617.

Fama, E.F. and French, K.R. (1997) Industry Costs of Equity, Journal of Financial Economics, 43, 153-193.

Kester, W.C. (1984) Today's Options for Tomorrow's Growth, Harvard Business Review, (March/April), 153-160.

Kester, W.C. (1986) An Options Approach to Corporate Finance, Chapter 5 in Altman, E.I. Handbook of Corporate Finance, John Wiles \& Sons. 
London Business School (Various issues) (Edited by Dimson, E., and March, P.R.), Risk Measurement Service, Institute of Finance and Accounting.

Majd, S., and Pindyck, R.S. (1987) Time to Build, Option Value, and Investment Decisions, Journal of Financial Economics, 18, 7-27.

Miller, M.H., and Modigliani, F. (1961) Dividend Policy, Growth and the Valuation of Shares, Journal of Business, 34(October), 411-433.

Myers, S.C. (1977) Determinants of Corporate Borrowing, Journal of Financial Economics, 5, 147-175.

Myers, S.C., and Turnbull, S.M. (1977) Capital Budgeting and the Capital Asset Pricing Model: Good News and Bad News, Journal of Finance, 32(2, May), 321-332.

O'Hanlon, J., and Steele, A. (1997) Estimating the Equity Risk Premium Using Accounting Fundamentals, Unpublished manuscript, Lancaster University/ University of Warwick.

Pindyck, R.S. (1988) Irreversible Investment, Capacity Choice, and the Value of the Firm, American Economic Review, 78(December), 969-985. 


\begin{tabular}{ccccccc}
\hline Year & No. & Mean & Median & Q1 & Q3 & $\begin{array}{c}\text { Mean - } \\
\text { continuing } \\
\text { firms }\end{array}$ \\
$\mathbf{1 9 8 7}$ & 189 & 52.61 & 54.52 & 43.06 & 64.90 & 52.74 \\
$\mathbf{1 9 8 8}$ & 194 & 50.43 & 51.26 & 41.94 & 61.45 & 50.15 \\
$\mathbf{1 9 8 9}$ & 208 & 57.30 & 57.52 & 48.46 & 67.05 & 57.54 \\
$\mathbf{1 9 9 0}$ & 211 & 53.84 & 54.00 & 44.25 & 63.21 & 54.64 \\
$\mathbf{1 9 9 1}$ & 226 & 59.84 & 62.23 & 54.15 & 68.23 & 61.13 \\
$\mathbf{1 9 9 2}$ & 223 & 61.11 & 63.00 & 53.60 & 70.62 & 62.30 \\
$\mathbf{1 9 9 3}$ & 242 & 58.07 & 62.05 & 50.44 & 69.36 & 60.13 \\
$\mathbf{1 9 9 4}$ & 254 & 56.47 & 59.27 & 51.51 & 66.34 & 58.13 \\
$\mathbf{1 9 9 5}$ & 263 & 54.16 & 57.25 & 46.50 & 63.73 & 56.06 \\
Total & 2010 & 56.12 & 58.19 & 47.43 & 66.64 & 56.95 \\
\hline
\end{tabular}

This table shows the mean, median and quartile values for the proportion of the market value of firms in the FTSE350 which is attributed to growth opportunities according to the Kester (1984) and Brealey and Myers (1981) (KBM) model. Values are calculated assuming a risk premium of $9 \%$ and a nominal rate of interest (UK inter bank 1 year middle rate). Earnings per share are calculated as the average of current earnings per share and the I/B/E/S forecast earnings per share for the next 12 months. From a total sample of 2082 observations, 72 (3.5\%) were excluded where the calculated value of growth opportunities was either negative (50 observations) or exceeded $100 \%$ of the share price (22 observations) (see hypothesis 1 ). The mean is also given for a subset of 172 firms for which growth opportunities could be calculated for each of the nine years examined. 
Exhibit 2: Sensitivity of Growth Opportunities Estimates to Measurement of Earnings Per Share

\begin{tabular}{|c|c|c|c|}
\hline YEAR & EPS $_{1 / 2}$ & $\mathbf{E P S}_{\mathbf{0}}$ & $\overline{\text { EPS }_{1}}$ \\
\hline 1987 & 52.61 & 56.11 & 50.14 \\
\hline 1988 & 50.43 & 53.47 & 47.68 \\
\hline 1989 & 57.30 & 60.03 & 54.56 \\
\hline 1990 & 53.84 & 55.41 & 52.11 \\
\hline 1991 & 59.84 & 62.64 & 56.79 \\
\hline 1992 & 61.11 & 62.57 & 57.46 \\
\hline 1993 & 58.07 & 60.59 & 56.11 \\
\hline 1994 & 56.47 & 58.91 & 54.16 \\
\hline 1995 & 54.16 & 56.97 & 51.60 \\
\hline Mean & 56.12 & 58.63 & 53.57 \\
\hline Median & 58.19 & 60.84 & 55.51 \\
\hline Q1 & 47.44 & 50.06 & 44.57 \\
\hline Q3 & 66.63 & 69.09 & 64.12 \\
\hline Percent $<0 \%$ & 2.4 & 1.9 & 3.1 \\
\hline Percent $>100 \%$ & 1.1 & 1.8 & 0.5 \\
\hline
\end{tabular}


Exhibit 3: The Sensitivity of Growth Opportunities to the Equity Risk Premium

\begin{tabular}{cccc}
\hline & \multicolumn{3}{c}{ Risk Premium } \\
$\mathbf{1 9 8 7}$ & 35.48 & $\mathbf{6 \%}$ & $\mathbf{9 \%}$ \\
$\mathbf{1 9 8 8}$ & 33.90 & 45.06 & 52.61 \\
$\mathbf{1 9 8 9}$ & 44.56 & 43.53 & 50.43 \\
$\mathbf{1 9 9 0}$ & 40.82 & 51.21 & 57.30 \\
$\mathbf{1 9 9 1}$ & 46.23 & 47.65 & 53.84 \\
$\mathbf{1 9 9 2}$ & 43.65 & 53.53 & 59.84 \\
$\mathbf{1 9 9 3}$ & 36.89 & 53.35 & 61.11 \\
$\mathbf{1 9 9 4}$ & 37.23 & 50.08 & 58.07 \\
$\mathbf{1 9 9 5}$ & 31.49 & 48.71 & 56.47 \\
& & 45.85 & 54.16 \\
$\mathbf{M e a n}$ & 38.92 & 48.89 & 56.12 \\
Median & 38.98 & 50.39 & 58.19 \\
$\mathbf{Q 1}$ & 26.91 & 38.79 & 47.44 \\
$\mathbf{Q 3}$ & 50.08 & 59.64 & 66.63 \\
Percent $<\mathbf{0 \%}$ & 10.5 & 4.7 & 2.4 \\
Percent $>\mathbf{1 0 0} \%$ & 1.1 & 1.1 & 1.1 \\
\hline The table displays the mean percentage value of PVGO with different equity risk \\
premia, assuming a nominal risk free interest rate.
\end{tabular}


Exhibit 4: The Sensitivity of Growth Opportunities to the Inflation Assumption

\begin{tabular}{cccc}
\hline & \multicolumn{3}{c}{ Risk Premium } \\
Year & $\mathbf{3 \%}$ & $\mathbf{6 \%}$ & $\mathbf{9 \%}$ \\
$\mathbf{1 9 8 7}$ & 19.42 & 25.93 & 35.39 \\
$\mathbf{1 9 8 8}$ & 19.67 & 23.56 & 28.87 \\
$\mathbf{1 9 8 9}$ & 23.91 & 25.79 & 31.88 \\
$\mathbf{1 9 9 0}$ & 28.60 & 26.04 & 28.60 \\
$\mathbf{1 9 9 1}$ & 20.61 & 31.88 & 43.53 \\
$\mathbf{1 9 9 2}$ & 25.98 & 39.58 & 50.65 \\
$\mathbf{1 9 9 3}$ & 23.90 & 40.60 & 52.76 \\
$\mathbf{1 9 9 4}$ & 22.39 & 36.76 & 47.73 \\
$\mathbf{1 9 9 5}$ & 19.10 & 32.98 & 45.68 \\
& & & \\
Mean & 22.67 & 33.33 & 41.87 \\
Median & 19.24 & 33.24 & 43.88 \\
$\mathbf{Q 1}$ & 9.51 & 18.60 & 26.58 \\
$\mathbf{Q 3}$ & 31.12 & 46.14 & 56.56 \\
Percent $<\mathbf{0 \%}$ & 61.0 & 29.4 & 12.1 \\
Percent $>\mathbf{1 0 0 \%}$ & 1.1 & 1.1 & 1.1 \\
\hline The table displays the mean percentage value of PVGO with different equity risk \\
premia, assuming a real risk free interest rate.
\end{tabular}




\section{Exhibit 5: Serial and Cross-Correlation Coefficients for Abnormal Returns}

Panel A: Correlation Coefficients for Abnormal Returns to the Components of the KBM Model Using Equal Betas

\begin{tabular}{lccccc}
\hline & $\mathbf{A B R g}_{\mathbf{t}}$ & $\mathbf{A B R x}_{\mathbf{t}}$ & $\mathbf{A B R e}_{\mathbf{t + 1}}$ & $\mathbf{A B R g}_{\mathbf{t + 1}}$ & $\mathbf{A B R x}_{\mathbf{t + 1}}$ \\
$\mathbf{A B R e}_{\mathbf{t}}$ & $0.2279^{* *}$ & $0.2194^{* *}$ & 0.0513 & -0.0276 & $0.1585^{* *}$ \\
$\mathbf{A B R g}_{\mathbf{t}}$ & & -0.0060 & 0.0187 & -0.0121 & 0.0296 \\
$\mathbf{A B R x}_{\mathbf{t}}$ & & & -0.0050 & 0.0083 & -0.0017 \\
$\mathbf{A B R e}_{\mathbf{+} \mathbf{1}}$ & & & & $0.2168^{* *}$ & $0.3125^{* *}$ \\
$\mathbf{A B R g}_{\mathbf{+} \mathbf{1}}$ & & & & & 0.0043 \\
\hline
\end{tabular}

Panel B:Correlation Coefficients for Abnormal Returns to the Components of the KBM Model Using Weighted Betas

\begin{tabular}{lccrcc}
\hline & $\mathbf{A B R g}_{\mathbf{t}}$ & $\mathbf{A B R x}_{\mathbf{t}}$ & $\mathbf{A B R e}_{\mathbf{t + 1}}$ & $\mathbf{A B R g}_{\mathbf{t + 1}}$ & \multicolumn{1}{c}{$\mathbf{A B R \mathbf { x }}_{\mathbf{t + 1}}$} \\
$\mathbf{A B R e}_{\mathbf{t}}$ & $0.2283^{* *}$ & $0.2229^{* *}$ & 0.0513 & -0.0280 & $0.1606^{* *}$ \\
$\mathbf{A B R g}_{\mathbf{t}}$ & & -0.0040 & 0.0189 & -0.0111 & 0.0248 \\
$\mathbf{A B R x}_{\mathbf{t}}$ & & & -0.0033 & 0.0064 & 0.0128 \\
$\mathbf{A B R e}_{\mathbf{t}+\mathbf{1}}$ & & & & $0.2173^{* *}$ & $0.3199^{* *}$ \\
$\mathbf{A B R g}_{\mathbf{t} \mathbf{1}}$ & & & & & 0.0074 \\
\hline
\end{tabular}

These tables show the serial and cross-correlations between the abnormal returns to the various components of the KBM model. Abnormal returns are calculated using CAPM. In exhibit 5 a we assume $8 g=8 x$, while in exhibit $5 b$ we assume $8 g=28 x$. ** Correlation is significant at the 0.01 level (2-tailed). 
Exhibit 6: Elasticity of the Components of the KBM Model

\begin{tabular}{|c|c|c|c|c|}
\hline Category & $\mathbf{N}$ & $\begin{array}{c}\text { Observed } \\
\text { proportion }\end{array}$ & Test proportion & $\begin{array}{c}\text { Asymp. Sig. } \\
\text { (2-tailed) }\end{array}$ \\
\hline $\begin{array}{l}\text { Elasticity } \\
\text { coefficient }<1\end{array}$ & 1217 & 0.72 & 0.50 & $0.000^{\mathrm{a}}$ \\
\hline $\begin{array}{l}\text { Elasticity } \\
\text { coefficient }>1\end{array}$ & 470 & 0.28 & & \\
\hline Total & 1687 & 1.00 & & \\
\hline
\end{tabular}

Table shows a binomial test of an elasticity coefficient calculated by dividing ABRg by $_{\mathrm{t}}$ $\mathrm{ABRx}_{\mathrm{t}}$. Abnormal returns have been calculated assuming $8 \mathrm{~g}=8 \mathrm{x}$.

a based on $\mathrm{Z}$ approximation. 


\section{NOTES}

${ }^{1}$ Thus despite Myers (1977) recognising the option not to replace assets-in-place, the KBM model does not value this option, but rather concentrates on the choice of whether or not to increase capacity.

${ }^{2}$ The methodology applied by Kester in his 1986 paper is not explicitly stated, although appears to be similar to that applied in his 1984 paper.

3 This paper is concerned with the measurement of the value of growth opportunities. Various papers have applied indicators of the presence of growth opportunities, such as market to book values of equity (Chung and Charoenwong, 1991, Barclay and Smith, 1995), and Tobin's Q (Ben-Horim and Callen, 1989). Such proxies for the value of growth opportunities are not analysed in this paper.

${ }^{4}$ Myers' more flexible presentation (1977) would appear to include the possibility that valuable growth opportunities could be firm-specific and hence, perhaps, linked to the continued ownership by the firm of assets with negative earning power. This alternative interpretation of growth opportunities is inconsistent with the KBM model, where the choice is whether or not to expand existing capacity. As previously discussed, an analysis of Myers' replacement options is outwith the scope of this paper.

${ }^{5}$ The database constructed for this study went back to 1986 . Full data was not available in earlier years. Since several tests involve prior year's data for the calculation of returns, results are reported for 1987-1995.

${ }^{6}$ The KBM model was proposed by authors who were obviously aware that company earnings are sometimes negative and that the model would not be applicable in these cases. To carry out further tests of the model in the appropriate context, we exclude the cases for which it fails the preliminary hurdle (i.e., where $\mathrm{Pg}<0$ or where $\mathrm{Pg}>\mathrm{Pe}$ ). In $2.4 \%$ of the cases (50 observations), the value of Pg was negative, and $1.1 \%$ of the cases (22 observations), Pg values exceeded 100\% (implying negative Px). These 
observations have been excluded from the analysis in exhibit 1. (It should also be noted that were these observations to be included, the statistics would suffer from major outlier problems, with the statistics being non-robust). 